\title{
The association between trust in health care providers and medication adherence among Black women with hypertension
}

\author{
Willie M. Abel ${ }^{1}$ * and Jimmy T. Efird ${ }^{2}$ \\ 1 School of Nursing, University of North Carolina at Charlotte, Charlotte, NC, USA \\ ${ }^{2}$ Department of Cardiovascular Sciences, Brody School of Medicine, East Carolina Heart Institute, East Carolina University, Greenville, NC, USA
}

\section{Edited by:}

Jie Hu, University of North Carolina at Greensboro, USA

\section{Reviewed by:}

Setor K. Kunutsor, University of Cambridge, UK

Jinbing Bai, University of North

Carolina at Chapel Hill, USA

Melanie M. Adams, Keene State

College, USA

*Correspondence:

Willie M. Abel, School of Nursing, The University of North Carolina at

Charlotte, 9201 University City Blvd, \#444F CHHS Bldg, Charlotte, NC

28223-0001, USA

e-mail:wmabel@uncc.edu
Background: Black women have the highest prevalence of hypertension in the world. Reasons for this disparity are poorly understood. The historical legacy of medical maltreatment of Blacks in the U.S. provides some insight into distrust in the medical profession, refusal of treatment, and poor adherence to treatment regimens.

Methods: Black women $(N=80)$ who were prescribed antihypertensive medications were recruited from urban communities in North Carolina. Study participants completed the Trust in Physician and Hill-Bone Compliance to High Blood Pressure Therapy questionnaires. An exact discrete-event model was used to examine the relationship between trust and medication adherence.

Results: Mean age of study participants was $48 \pm 9.2$ years. The majority of participants (67\%) were actively employed and $30 \%$ had incomes at or below the federal poverty level. Increasing levels of trust in the health care provider was independently associated with greater medication adherence $\left(P_{\text {Trend }}=0.015\right)$.

Conclusion: Black women with hypertension who trusted their health care providers were more likely to be adherent with their prescribed antihypertensive medications than those who did not trust their health care providers. Findings suggest that trusting relationships between Black women and health care providers are important to decreasing disparate rates of hypertension.

Keywords: trust, medication adherence, Black women, hypertension, health care provider

\section{INTRODUCTION}

Mutual trust is essential to the patient/heath care provider relationship and the achievement of positive health outcomes. To be trustworthy, health care providers need to show competence, caring behaviors, good interpersonal skills, and a desire to promote the health of the patients they serve $(1,2)$. Likewise, trustworthy patients need to be honest, adhere to the treatment regimen, and perform self-care behaviors (2). Trust is not assumed, but it can be earned over time as the patient and health care provider get to know each other by working together to ensure that accurate medical conclusions are obtained and the best course of treatment is determined and executed (1). Similarly, a patient's trust in the health care provider implies confidence that their words are truthful and actions are appropriate in the provision of care and treatment (1). When health care providers trust their patients, it implies a belief that the patient will seek timely health care, reveal sensitive information, and follow the recommended treatment regimen (1).

The historical legacy of Blacks in the U.S. provides insight as to why distrust in the medical profession exists. Introduced to the U.S. as slaves, Blacks had little to no human rights. Frequently, they were used in experiments by White doctors to perfect medical and surgical techniques before attempting procedures on Whites (3-5). Because of skin color and other distinctive features such as hair texture, thick lips, and body shape, the lives of Blacks were not valued, and their exploitation by White physicians endured a long history (3-5). Myths were invented by the medical community to portray Blacks as different, inferior, and less than human. These myths resulted in the enactment of laws in the U.S. that distinguished Black people as property on the same level with livestock and beast of burden $(5,6)$. Published journal articles and doctors records on various types of medical experimentation with Blacks spanned several centuries. Examples of experiments included: unanesthetized gynecological experiments on slave women; Tuskegee syphilis study that withheld treatment to plot disease progress in men; eugenic-inspired involuntary sterilizations of welfare mothers with multiple children; unconsented high dose radiation experiments; and hazardous dermatological research on prison subjects (4).

Present treatment related issues also influence distrustful relationships between Blacks and health care providers. In the landmark Institute of Medicine report $(7,8)$, research indicated that minority/ethnic groups are less likely than Whites to receive needed services, procedures, and routine treatments for common 
health problems and for diseases such as cancer, cardiovascular disease, and diabetes. In cardiac care for example, minorities are less likely to receive pharmacological therapy, transplants, catheterization, and bypass surgery even when treatments and procedures are judged to be appropriate $(7,8)$. In contrast, they are more likely to receive lower quality care and undesirable procedures such as lower extremity amputations for diabetes. Equally perplexing is the strong link related to finances and access to cardiac care (9) that often results in discriminatory practices for poor people. It is also daunting to consider that discriminatory practices persist even in Blacks and other minority/ethnic groups who have the ability to pay for health care services (10). Thus, the maltreatment experienced by Blacks in the health care arena contributes not only to distrust, but also refusal of treatment and poor adherence to treatment regimens $(3,7)$. Today, remnants of history continue in subtle configurations resulting in many Blacks approaching health care with fear, skepticism, and caution (3).

Currently, disparate rates of heart disease, kidney disease, and stroke associated with uncontrolled hypertension (HTN) in Blacks who reside in the U.S are perplexing. When the prevalence of HTN is delineated by race and sex, HTN is greater for Black women $(47 \%)$, followed by Black men $(43 \%)$, then White men (33\%) and White women (31\%), and is lowest for Hispanic men (30\%) and women (29\%) (11). These statistics are especially concerning because Black women are cited as having the highest prevalence of HTN in the U.S. and worldwide, and rates are increasing (11). Thus, alleviating sources that potentiate nonadherence to treatment regimens such as medication adherence is important. One factor, mistrust in health care providers among Black women with hypertension may potentially lead to poorer medication adherence. To our knowledge, no studies have examined the association of trust and adherence to antihypertensive medications in an exclusively Black female population. Therefore, this study examined the association between trust in health care providers and medication adherence among these Black women.

\section{MATERIALS AND METHODS STUDY SAMPLE}

A cross-sectional pilot study was conducted with hypertensive Black women in the Piedmont region of North Carolina. Methods used in this study have been reported elsewhere and are briefly described here (12). Inclusion criteria included (a) ages ranging from 18 to 60 years, (b) taking one or more prescription medication(s) for HTN, and (c) English speaking. Exclusion criteria included self-report of (a) mental illness that interfered with daily functioning, (b) current pregnancy, or (c) concurrent participation in another research study. Using an a priori adaptive algorithm to compute power, a sample size of 80 was required to detect an effect size of 4.5 (alpha of 0.05 ) with power of $80.9 \%$, assuming a referent event rate of 0.4 (13). Recruitment efforts included distributing flyers to various Black communities and businesses such as hair salons, churches, and community events, along with social nomination. Informed consent was obtained from all participants who met eligibility criteria and agreed to participate in the study. Data were collected in a private setting to ensure participant privacy. Questionnaires were generally completed in a 1-hour session.
Approval was obtained from the Institutional review board at the University of North Carolina at Greensboro.

\section{MEASURES}

Standardized instruments were used to gather information on medication adherence and trust in the health care provider among study participants. Demographic data (e.g., education, income, medical history, etc.) and anthropometric measurements (e.g., blood pressure, height, weight, and waist circumference) also were collected.

\section{Trust in Physician Scale}

The Trust in Physician Scale (TPS) is an 11-item tool that measures patient trust in their physician (14). In the current study, the word "physician" was replaced with "health care provider" because of the likelihood that patients would be seen by mid-level providers such as nurse practitioners or physician assistants. Responses on the TPS are scored on a five-point Likert scale from 1 (strongly agree) to 5 (strongly disagree). "Neutral" was not used as a response item. This was done in an effort to force participants to express their opinion to specific responses because neutral data would not provide meaningful information. Scores can range from 11 to 55 with higher scores indicating greater trust. Four items are reverse scored to prevent repetitive responses. Cronbach's alphas for the TPS ranged from 0.85 to 0.90 in a previous study (14) and alpha was 0.835 for this study.

\section{Hill-Bone Compliance to High Blood Pressure Therapy Scale}

The Hill-Bone Compliance to High Blood Pressure Therapy Scale (CHBPTS) is a 14-item tool used to assess antihypertensive medication adherence and has been reported elsewhere (12). In this study, "compliance" was replaced by "adherence" because of the passivity associated with the word "compliance" that hinders the establishment of a working relationship with the person $(15,16)$. Included in the Hill-Bone CHBPTS is the four-item Medication Adherence Scale (MMAS) developed by Morisky et al. $(17,18)$. The Hill-Bone CHBPTS includes three subscales, and for this study only the medication subscale (eight items) was chosen to assess medication-taking behavior plus one item that addressed prescription refills. Responses are scored on a four-point Likert scale from 1 ("none of the time") to 4 ("all the time"). The minimal medication-taking score is 9 and the maximum score is 36 . Lower scores reflect medication adherence behaviors and higher scores represent non-adherence. Cronbach's alpha for the medication subscale was 0.77 in a previous study (19) and alpha was 0.843 for this study.

\section{DATA ANALYSIS}

Descriptive statistics were used to characterize the sample and study tools. Cronbach's alpha measured internal reliability of the instruments and a consistency of 0.70 or higher are considered acceptable and values of 0.60 or higher are marginally acceptable (20). The exact discrete-event (proportional odds) model is a log-linear procedure that is especially suited for analyzing ordinal outcomes with non-normally distributed error terms (21). Relative importance scores (RIS), denoting the proportional odds of a higher (or lower) outcome score for a specific level of a predictor variable compared with referent group, were computed 
using this model. $P$ values for linear trend across levels of a predictor variable were computed using a likelihood ratio test. Variables were included in the optimal predictive model if, for at least one level of a predictor variable, $p<0.025$ and RIS $>2.5$ or RIS $<0.4$. The post hoc addition of other variables into the final model was determined in a systematic, pairwise fashion, based upon a $10 \%$ increase or decrease in the magnitude of levels for the main effect variable (e.g., trust in the health care provider). All statistics were computed using SAS version 9.3 (Cary, NC, USA).

\section{RESULTS}

Participants in the sample ranged in age from 19 to 60 years, with the majority aged 50 or older. Approximately $68 \%$ were not married, $33 \%$ were unemployed or retired, and over $70 \%$ were obese. A total of $84 \%$ had completed high school or a higher level of education (see Table 1). The duration of antihypertensive medication treatment for participants ranged from 1 month to 37 years (mean $10.2 \pm$ SD 8.6, median 10). Of the 20 participants who claimed complete adherence to their antihypertensive medications, the majority were in the $50-60$ age group $(n=12)$. The instruments used in the study had acceptable internal reliability (Cronbach's alpha $\geq 60 \%$ ). The median score for participant's trust in their primary health care provider was above the mean of possible values (mean 43.9 \pm SD 6.3, median 45.0), with a score of 55 indicating perfect trust. The median score for participant's adherence to antihypertensive medication was below the mean of possible values (mean 13.1 \pm SD 4.2, median 12.5), with a score of 9 indicating perfect adherence.

Three univariable variables that predicted medication adherence were participant age, number of medications, and trust in health care provider (see Table 2). All age groups (Q2-Q4) were less likely to be adherent but participants in the 40-49 age group (Q3) had the highest RIS score and were 3.6 fold less likely to be adherent to antihypertensive medications than baseline $(\mathrm{Q} 1)$ ( $P$ for trend $=0.028)$. In contrast participants who reported taking five to seven medications (Q3) were 3.8 fold more likely to be adherent than baseline (Q1) $(p=0.001)$. However, a significant linear trend was not observed for "number of medications." The third univariable variable that predicted medication adherence was trust in health care provider. Participants who scored in the highest trust group Q4 (>52) were 16.7 fold more likely to be adherent than baseline (Q1) ( $P$ for trend $=0.010)$.

Variables retained in the "optimal predictive model" included participant age, number of medications, and trust in health care provider (see Table 2 ). Again all age groups were less likely to be adherent, but participants in the 40-49 age group (Q3) had the highest RIS score and were 3.7 fold less likely to be adherent to antihypertensive medications than baseline (Q1) ( $P$ for trend $=0.0036)$. Whereas participants who reported taking five to seven medications (Q3) were 3.6 fold more likely to be adherent than baseline (Q1) ( $p=0.0048)$. However, similar to the univariable case, a significant linear trend was not observed for "number of medications." Participants who scored in the highest trust group Q4 (>52) were 33.3 fold more likely to be adherent than baseline (Q1) ( $P$ for trend $=0.015$ ).
Table 1 | Sample characteristics and demographics $(N=80)$

\begin{tabular}{|c|c|}
\hline Characteristics & $N(\%)$ or mean $( \pm S D)$ \\
\hline Age & $47.8( \pm 9.2)$ \\
\hline \multicolumn{2}{|l|}{ Marital status } \\
\hline Single (never married) & $22(28)$ \\
\hline Married & $26(33)$ \\
\hline Separated & $9(11)$ \\
\hline Divorced & $16(20)$ \\
\hline Widowed & 7 (9) \\
\hline \multicolumn{2}{|l|}{ Employment status } \\
\hline Employed & $54(68)$ \\
\hline Unemployed/disabled & $24(30)$ \\
\hline Retired & $2(3)$ \\
\hline Comorbidities & $2.8( \pm 1.6)$ \\
\hline Number of medications & $5.1( \pm 3.6)$ \\
\hline \multicolumn{2}{|l|}{$\mathrm{BP}$} \\
\hline SBP mean & $135.2( \pm 19.8)$ \\
\hline DBP mean & $81.3( \pm 12.6)$ \\
\hline BMI & $36.8( \pm 10.4)$ \\
\hline \multicolumn{2}{|l|}{ Subscales } \\
\hline Underweight $\left(<18.5 \mathrm{~kg} / \mathrm{m}^{2}\right)$ & $1(1)$ \\
\hline Normal weight $\left(18.5-24.9 \mathrm{~kg} / \mathrm{m}^{2}\right)$ & $9(11)$ \\
\hline Overweight $\left(25-29.9 \mathrm{~kg} / \mathrm{m}^{2}\right)$ & $10(13)$ \\
\hline Obesity $\left(\geq 30 \mathrm{~kg} / \mathrm{m}^{2}\right)$ & $60(75)$ \\
\hline \multicolumn{2}{|l|}{ Education } \\
\hline Less than 12th grade & $13(16)$ \\
\hline High school graduate & $16(20)$ \\
\hline GED or equivalent & $1(1)$ \\
\hline Some community college & $11(14)$ \\
\hline Graduated community college & $6(8)$ \\
\hline Some 4-year college & $5(6)$ \\
\hline Graduated 4-year college & $10(13)$ \\
\hline Some graduate school & $2(3)$ \\
\hline Completed graduate school & $6(8)$ \\
\hline Completed trade or vocational school & $10(13)$ \\
\hline \multicolumn{2}{|l|}{ Income } \\
\hline$<\$ 10,000$ & $15(19)$ \\
\hline$\$ 10,000-14,999$ & $4(5)$ \\
\hline$\$ 15,000-19,999$ & $10(13)$ \\
\hline$\$ 20,000-24,999$ & $8(10)$ \\
\hline$\$ 25,000-\$ 34,999$ & $10(13)$ \\
\hline$\$ 35,000-\$ 44,999$ & $12(15)$ \\
\hline$\$ 45,000-54,999$ & $6(8)$ \\
\hline$\$ 55,000-64,999$ & $6(8)$ \\
\hline$\$ 65,000-74,999$ & $3(4)$ \\
\hline$\$ 75,000-\$ 99,999$ & $3(4)$ \\
\hline$\$ 100,000$ and over & $2(3)$ \\
\hline Refused & $1(1)$ \\
\hline
\end{tabular}

Percentages rounded.

$B P=$ blood pressure; $S B P=$ systolic blood pressure; $D B P=$ diastolic blood pressure; $B M I=$ body mass index. 
Table 2 | Exact discrete-event model for compliance scale (range =9-33).

\begin{tabular}{|c|c|c|c|c|}
\hline \multirow[t]{2}{*}{ Characteristics } & \multicolumn{2}{|c|}{ Univariable predictors } & \multicolumn{2}{|c|}{ Optimal predictive model } \\
\hline & Crude RIS & $95 \% \mathrm{Cl}$ & Adjusted RIS & $95 \% \mathrm{Cl}$ \\
\hline Q1 (<41) (Low) & 1.0 & Referent & 1.0 & Referent \\
\hline Q2 (41-45) & 0.86 & $0.44-1.7(p=0.66)$ & 0.84 & $0.40-1.8(p=0.65)$ \\
\hline Q3 (46-52) & 0.57 & $0.28-1.2(p=0.12)$ & 0.64 & $0.29-1.4(p=0.26)$ \\
\hline Q4 (>52) (high) & & $P_{\text {Trend }}=0.010^{\S}$ & & $P_{\text {Trend }}=0.015^{\S}$ \\
\hline \multicolumn{5}{|l|}{ Patient age (years) } \\
\hline $\mathrm{Q} 1(>55)$ & 1.0 & Referent & 1.0 & Referent \\
\hline Q2 (50-55) & 2.3 & $1.1-4.9(p=0.029)$ & 2.9 & $1.3-6.5(p=0.011)$ \\
\hline Q3 (40-49) & 3.6 & $1.6-8.0(p=0.001)$ & 3.7 & $1.6-8.6(p=0.0028)$ \\
\hline $\mathrm{Q} 4(<40)$ & 2.4 & $1.02-5.4(p=0.044)$ & 3.2 & $1.3-8.2(p=0.013)$ \\
\hline Q2 (3-4) & 0.56 & $0.28-1.1(p=0.11)$ & 0.47 & $0.22-0.99(p=0.047)$ \\
\hline Q3 (5-7) & 0.26 & $0.12-0.59(p=0.001)$ & 0.28 & $0.12-0.68(p=0.0048)$ \\
\hline \multirow[t]{2}{*}{ Q4 (8-18) } & 0.65 & $0.31-1.4(p=0.25)$ & 0.73 & $0.34-1.6(p=0.45)$ \\
\hline & & $P_{\text {Trend }}=0.11^{\S}$ & & $P_{\text {Trend }}=0.35^{\S}$ \\
\hline
\end{tabular}

"Lower scores reflect medication adherent behaviors and higher scores reflect non-adherent behaviors. ${ }^{5}$ Likelihood ratio trend test. RIS $=$ Relative Importance Score; $\mathrm{Cl}=$ confidence intervals; $Q=$ quartile.

Thus, increasing levels of trust in the health care provider was associated with greater medication adherence (optimal predictive model; Q1: RIS $=1.0$; Q2: $\mathrm{RIS}=0.84,95 \% \mathrm{CI}=0.40-1.8$; Q3: $\mathrm{RIS}=0.64,95 \% \mathrm{CI}=0.29-1.4$; Q4: RIS $=0.03,95 \% \mathrm{CI}=0.004-$ 0.23 ; $\left.P_{\text {Trend }}=0.015\right)$, independent of age and number of medications (see Table 2). In summary, participant age was the variable that independently predicted non-adherence to antihypertensive medications and trust was the only variable that independently predicted adherence to antihypertensive medications in our "optimal predictive model."

\section{DISCUSSION}

To date, studies on trust and medication adherence have been conducted primarily with Black men (22). Other studies have included both Black and White men and women but did not specifically target Black females (23). The current study represents the first to examine the association between trust and medication adherence in an exclusively Black female population.

Several studies have cited distrust of the medical community as the rationale for non-adherent health behaviors (2, 24-26). Blacks often mention the Tuskegee experiments and medical injustices experienced personally or by family members and friends. These injustices, along with issues such as racism, discrimination, access to care, financial barriers, thoughts of being experimented on, and substandard health care affect the ability of Blacks to trust the medical community (2). Consequently, many Blacks are reluctant to seek health care or follow medical advice resulting in non-adherence to the treatment regimen and subsequent health problems $(2,26-28)$. Thus, antihypertensive medication non-adherence, is likely to result in poor blood pressure control with greater organ damage such as heart failure, kidney disease, myocardial infarction, and stroke (11).

In the current study, all age groups were less likely to be adherent to their antihypertensive medications, but the greatest predictor was participants aged 40-49. These findings differ from those of other studies. For example, Schoenthaler et al. (29) reported that younger Blacks exhibited more non-adherent medication behaviors. In addition, Weingarten and Cannon (30) reported lower adherence to antihypertensive medications among those younger than age 55 and older than age 65 . A higher percentage of participants over age 50 in our study indicated medication adherence compared to those less that age 50. One explanation for less adherence to antihypertensive medications among those aged 40-49 could be the stressors of marriage, working, and family responsibilities because women at this age are more likely to be married or separated, work full- or part-time, and live in households with more people than those in the other age groups.

Furthermore, participants in our study who took five to seven medications were more likely to be adherent to their medication regimen. This finding was not consistent with the literature which reports that fewer medications equate to better adherence (31, 32). Perhaps those with a higher number of medications perceived themselves as sicker and were therefore more adherent. Also, the increased number of medications may have serendipitously contributed to frequent visits to the health care provider that fostered better communication, trust, and engagement in self-care and medication adherence. 
Participants in this study who reported the most trust in their health care providers were more adherent to their prescribed antihypertensive medications. This finding is consistent with the view that trust promotes better medication adherence (29,33). Nguyen et al. (34) used the same instruments to measure trust and medication adherence as those used in the current study and found that higher adherence was associated with greater trust in the health care provider in participants with inflammatory bowel disease (IBO). One major difference between the two diagnostic groups that may influence adherence is that IBO has symptoms and HTN is silent.

The issue of poor adherence in Black women with HTN is multifactorial and complicated by cultural, psychosocial, socioeconomic, environmental, physiological, and genetic influences (35). Health care providers need to understand how these processes influence the health and behaviors of patients and potentially simulate rebellion, conflict, and mistrust in relationships with providers (36). The enormity of the multifaceted and ubiquitous nature of adherence sheds light on the limited success of adherence research and interventions. Therefore it is vital that health care providers devise strategies to alter the processes and systems that influence the health status of individuals and populations and empower groups and individuals to work on their own behalf (36). Thus, future research aimed at involving the patient as a participant in their health care may be a key factor to devising strategies that influence the multifaceted nature of non-adherence and mistrust of health care providers.

Interestingly, it is well documented that antihypertensive medications have proven efficacy in lowering blood pressure when patients adhere to the treatment regimen (37-40). However, many Black women have not readily participated in risk reduction behaviors to manage and prevent HTN (41-43). One possible explanation for the lack of adherence to treatment regimens may be attributed to the effect that past medical injustices have on present health behaviors. Distrust in health care providers is a potential barrier to medication adherence among Black women with hypertension. Our study found that increased trust was associated with greater medication adherence. Thus, it is important that health care providers and Blacks with HTN find ways to transcend the effects of history, restore trust in the health system, and form collaborative relationships to foster optimal health care.

\section{LIMITATIONS}

Several limitations were noted in this study. The use of selfreport measures may introduce personal bias. Moreover, the small convenience sample limits the generalizability of the findings to other populations in different regions of the U.S. Future studies could increase the representativeness of the sample by recruiting participants from geographically diverse sites. In addition, other factors besides trust in the health care provider may impact medication adherence in Black women with HTN. Additional research is needed to identify other contributing factors that are associated with improving medication adherence and blood pressure control among Black women. Lastly, this was a nonrandomized, cross-sectional study, and causal inferences cannot be made.

\section{CONCLUSION}

In this study, Black women were more likely to be adherent to antihypertensive medications if they had a higher level of trust in their health care provider. Understanding trust issues in Black women is essential when considering their disproportionate burden of HTN. Future research should explore methods for health care providers to deliver culturally sensitive care and establish trusting interpersonal relationships with Black women.

\section{REFERENCES}

1. Jacobs AK. Rebuilding an enduring trust in medicine: a global mandate: presidential address American Heart Association Scientific Sessions 2004. Circulation (2005) 111:3494-8. doi:10.1161/CIRCULATIONAHA.105. 166277

2. Jacobs EA, Rolle I, Ferrans CE, Whitaker EE, Warnecke RB. Understanding African Americans' views of the trustworthiness of physicians. J Gen Intern Med (2006) 21(6):642-7. doi:10.1111/j.1525-1497.2006.00485.x

3. Gamble VN. Under the shadow of Tuskegee: African Americans and health care. Am J Public Health (1997) 87(11):1773-8. doi:10.2105/AJPH.87.11.1773

4. Washington HA. Medical Apartheid: The Dark History of Medical Experimentation on Black Americans from Colonial Times to the Present. New York: Anchor Books (2006). p. 157-85.

5. Spillers HJ. Mama's baby, papa's maybe: an American grammar book. Diacritics (1987) 17:65-81. doi:10.2307/464747

6. Smedley A. Origin of the Idea of Race. Anthropology Newsletter [Internet]. (1997). Available from: Public Broadcasting Service: http://www.pbs.org/race/ 000_About/002_04-background-02-09.htm.

7. Unequal Treatment: What Healthcare Providers Need to Know About Racial and Ethnic Disparities in Health Care. Available from: http://www.iom.edu/ / media/Files/Report\%20Files/2003/Unequal-Treatment-Confronting-Racialand-Ethnic-Disparities-in-Health-Care/Disparitieshcproviders8pgFINAL.pdf.

8. Smedley BD, Stith AY, Nelson AR editors. Unequal Treatment: Confronting Racial and Ethnic Disparities in Health Care. Washington, DC: The National Academies Press (2003).

9. Mayberry RM, Mili F, Ofili E. Racial and ethnic differences in access to medical care. In: LaVeist TA editor. Race, Ethnicity, and Health: A Public Health Reader. San Francisco, CA: Jossey-Bass (2002). p. 163-97.

10. Kennedy BR, Mathis CC, Woods AK. African Americans and their distrust of the health care system: healthcare for diverse populations. J Cult Divers (2007) 14(2):56-60.

11. Go AS, Mozaffarian D, Roger VL, Benjamin EJ, Berry JD, Borden WB, et al. Heart disease and stroke statistics - 2013 update: a report from the American Heart Association. Circulation (2013) 127:e6-245. doi:10.1161/CIR. 0b013e318282ab8f

12. Abel WM, Crane PB. Predictors of depression in Black women with hypertension. Issues Ment Health Nurs (Forthcoming 2014).

13. Efird J. An adaptive algorithm to compute power for the Hochberg sequential rejective procedure: a correlated data example. Western Users of SAS System Proceedings; Paper 2581-2007. San Francisco, CA (2007).

14. Anderson LA, Dedrick RF. Development of the trust in physician scale: a measure to assess interpersonal trust in patient-physician relationships. Psychol Rep (1990) 67:1091-100. doi:10.2466/PR0.67.7.1091-1100

15. Singleton T. How to improve patient adherence. Podiatr Manag (2008) 27(8):145-6.

16. Horne R, Weinman J, Barber N, Elliott R, Morgan M. Concordance, Adherence and Compliance in Medicine Taking. (2005). Available from: National Health Service: http://www.academia.edu/855004/Concordance_Adherence_ and_Compliance_in_Medicine_Taking

17. Morisky DE, Green LW, Levine DM. Concurrent and predictive validity of a self reported measure of medication adherence. Med Care (1986) 24:67-74. doi:10.1097/00005650-198601000-00007

18. Hill MN, Bone LR, Kim MT, Miller DJ, Dennison CR, Levine DM. Barriers to hypertension care and control in young urban Black men. Am J Hypertens (1999) 12:951-8. doi:10.1016/S0895-7061(99)00121-1

19. Kim MT, Han H, Hill MN, Rose L, Roary M. Depression, substance use, adherence behaviors, and blood pressure in urban hypertensive Black men. Ann Behav Med (2003) 26:24-31. doi:10.1207/S15324796ABM2601_04 
20. Gliner JA, Morgan GA. Research Methods in Applied Settings: An Integrated Approach to Design and Analysis. Mahwah, NJ: Lawrence Erlbaum Associates (2000).

21. Breslow NE, Day NE. Statistical Methods in Cancer Research, Vol 1, The Analysis of Case-Control Studies (IARC Scientific Publications No 32). Lyon: International Agency for Research on Cancer (1980).

22. Elder K, Ramamonjiarivelo Z, Wiltshire J, Piper C, Horn WS, Gilbert KL, et al. Trust, medication adherence, and hypertension control in Southern African American men. Am J Public Health (2012) 102(12):2242-5. doi:10.2105/AJPH. 2012.300777

23. Durant RW, McClure LA, Halanych JH, Lewis CE, Prineas RJ, Glasser SP, et al. Trust in physicians and blood pressure control in Blacks and Whites being treated for hypertension in the REGARDS study. Ethn Dis (2010) 20(3): 282-9.

24. Lukoschek P. African American's beliefs and attitudes regarding hypertension and its treatment: a qualitative study. J Health Care Poor Underserved (2003) 14(4):566-87. doi:10.1353/hpu.2010.0690

25. Martins D, Norris K. Hypertension treatment in African Americans: physiology is less important than sociology. Cleve Clin J Med (2004) 71(9):735-43. doi:10.3949/ccjm.71.9.735

26. Peters RM, Aroian KJ, Flack JM. African American culture and hypertension prevention. West J Nurs Res (2006) 28:831-54. doi:10.1177/0193945906289332

27. Fongwa MN, Evangelista LS, Hays RD, Martins DS, Elashoff D, Cowan MJ, et al. Adherence treatment factors in hypertensive African American women. Vasc Health Risk Manag (2008) 4:157-66. doi:10.2147/vhrm.2008.04.01.157

28. Wexler R, Elton T, Pleister A, Feldman D. Barriers to blood pressure control as reported by African American patients. J Natl Med Assoc (2009) 101(6): 597-603.

29. Schoenthaler A, Chaplin WF, Allengrante JP, Fernandez S, Diaz-Gloster M, Tobin JN, et al. Provider communication effects medication adherence in hypertensive African Americans. Patient Educ Couns (2009) 75(2):185-91. doi:10.1016/j.pec.2008.09.018

30. Weingarten MA, Cannon BS. Age as a major factor affecting adherence to medication for hypertension in a general practice population. Fam Pract (1988) 5(4):294-6. doi:10.1093/fampra/5.4.294

31. Gradman AH, Basile JN, Carter BL, Bakris GL. Combination therapy in hypertension. J Am Soc Hypertens (2010) 4(2):90-8. doi:10.1016/j.jash.2010.02. 005

32. Munger MA, Van Tassell BW, LaFleur J. Medication nonadherence: an unrecognized cardiovascular risk factor. MedGenMed (2007) 9(3). Available from: http://www.medscape.com/viewarticle/561319_4.

33. Benkert R, Hollie B, Nordstrom CK, Wickson B, Bins-Emerick L. Trust, mistrust, racial identity and patient satisfaction in urban African American primary care patients of nurse practitioners. J Nurs Scholarsh (2009) 41(2):211-9. doi:10.1111/j.1547-5069.2009.01273.x

34. Nguyen GC, LaVeist TA, Harris ML, Datta LW, Bayless TM, Brant SR. Patient trust-in-physician and race are predictors of adherence to medical management in inflammatory bowel disease. Inflamm Bowel Dis (2009) 15(8):1233-9. doi:10.1002/ibd.20883
35. Yancy CW, Benjamin EJ, Fabunmi RP, Bonow RO. Discovering the full spectrum of cardiovascular disease: minority health summit 2003 executive summary. Circulation (2005) 111(10):1339-49. doi:10.1161/01.CIR.0000157740.93598.51

36. Butterfield PG. Thinking upstream: nurturing a conceptual understanding of the societal context of health behavior. 3rd ed. In: Kenney JW editor. Philosophical and Theoretical Perspectives for Advanced Nursing Practice. Boston: Jones and Bartett (2002). p. 185-91.

37. Mabotuwana T, Warren J, Kennelly J. A computational framework to identify patients with poor adherence to blood pressure lowering medication. Int J Med Inform (2009) 78:745-56. doi:10.1016/j.ijmedinf.2009.06.006

38. Fongwa MN, Evangelista LS, Doering LV. Adherence to treatment factors in hypertensive African American women. J Cardiovasc Nurs (2006) 21:201-7. doi:10.1097/00005082-200605000-00008

39. Martins D, Gor D, Teklehaimanot S, Norris K. High blood pressure knowledge in an urban African-American community. Ethn Dis (2001) 11(1):90-6.

40. Chobanian AV, Bakris GL, Black HR, Cushman WC, Green LA, Izzo JL, et al. The Seventh Report of the Joint National Committee on Prevention, Detection, Evaluation, and Treatment of High Blood Pressure. Bethesda, MD: U. S. Department of Health and Human Services, National Institutes of Health (NIH Publication No. 04-5230) (2004).

41. Smith SC, Clark LT, Cooper RS, Daniels SR, Kumanyika SK, Ofili E, et al. Discovering the full spectrum of cardiovascular disease: minority health summit 2003: report of the obesity, metabolic syndrome, and hypertension writing group. Circulation (2005) 111(10):e134-9. doi:10.1161/01.CIR.0000157743.54710.04

42. Webb MS, Gonzalez LO. The burden of hypertension: mental representations of African American women. Issues Ment Health Nurs (2006) 27(3):249-71. doi:10.1080/01612840500502742

43. Benjamin EJ, Jessup M, Flack JM, Krumholz HM, Liu K, Nadkarni VM, et al. Discovering the full spectrum of cardiovascular disease: minority health summit 2003: report of the outcomes writing group. Circulation (2005) 111:e124-33. doi:10.1161/01.CIR.0000157742.95689.65

Conflict of Interest Statement: The authors declare that the research was conducted in the absence of any commercial or financial relationships that could be construed as a potential conflict of interest.

Received: 03 September 2013; paper pending published: 25 September 2013; accepted: 21 November 2013; published online: 05 December 2013.

Citation: Abel WM and Efird JT (2013) The association between trust in health care providers and medication adherence among Black women with hypertension. Front. Public Health 1:66. doi: 10.3389/fpubh.2013.00066

This article was submitted to Epidemiology, a section of the journal Frontiers in Public Health.

Copyright (c) 2013 Abel and Efird. This is an open-access article distributed under the terms of the Creative Commons Attribution License (CC BY). The use, distribution or reproduction in other forums is permitted, provided the original author(s) or licensor are credited and that the original publication in this journal is cited, in accordance with accepted academic practice. No use, distribution or reproduction is permitted which does not comply with these terms. 